\title{
EN BUSCA D'UNA MINORIA PERDUDA: NOTÍCIES SOBRE ELS MUDÉJARS DE XÀTIVA
}

\author{
Isabel Bonet $\mathrm{O}^{\prime}$ Connor
}

La història dels mudéjars ha experimentat canvis considerables en les darreres dècades a Espanya i a l'estranger. En el nou context polític, social i econòmic, els mudéjars han adquirit una importància que no tenien abans, convertint-se en una part important de la nostra història. El problema principal a l'hora d'escriure la història d'aquesta minoria conquerida és el fet de que la majoria de la informació prové dels arxius dels conqueridors. En la gran majoria dels casos, els mudéjars no ens parlen directament amb la seua veu, sinó que ho fan mitjançant la veu dels seu conqueridors, els cristians, la qual descriu el món dels mudéjars des del seu punt de vista.

És ben sabut de tots que els arxius cristians contenen una gran quantitat de documentació sobre els mudéjars. És fonamental per tal d'escriure la història d'una minoria sotmesa el consultar totes les fonts de documentació possibles, tant als arxius majors, com als menors o menys consultats. Açò és especialment important en el cas dels mudéjars de Xàtiva. La guerra de successió de 1707 tingué consequències negatives per a Xàtiva. La majoria de la documentació que hi havia desaparegué quan Felip Vè cremà la ciutat. Consegüentment, els mudéjars de Xàtiva, així com molts d'altres aspectes importants de la història d'aquesta ciutat han estat, fins ara, silenciats.

La meua tesi doctoral en curs és un esforç per tal de proporcionar veu a aquesta minoria oblidada. El que presente ací no és el resultat de la recerca als arxius majors, sinó el producte de la meua investigació a arxius menors, és a dir, l'arxiu de la Seu de Xàtiva, i a arxius menys consultats, com l'Archivo Histórico Nacional a Madrid. Un total de cinc documents provenents d'aquests arxius, i que daten de la primera meitat del segle catorze, ens proporcionen informació sobre la situació econòmica dels mudéjars del terme de Xàtiva, el seu contacte amb cristians a nivell econòmic i legal, la influència que els cristians exercien sobre els mudéjars a les zones rurals, la resposta que els mudéjars oferien a la pressió cristiana, etc. Aquesta documentació complementa la informació trobada als arxius majors i ens ajuda a 
entendre una multitud d'aspectes sobre els mudéjars que encara estan per resoldre.

El primer document que presente ací prové de l'Archivo Histórico Nacional a Madrid, de la col-lecció de pergamins del convent de cistercencs de Valldigna. El document presenta una disputa entre Xàtiva i el monestir de Valldigna, la qual es centra en una qüestió de jurisdicció sobre dos mudéjars del terme de Xàtiva.

El monestir cistercenc de Valldigna fou establert per Jaume II en 1298. Jaume II passava per la Vall d'Alfàndec de volta d'una campanya contra els sarraïns a Múrcia i Almeria, quan se n'adonà de que la vall era digna d'un monestir. El document de fundació donà als monjos de Santes Creus "tota la vall mencionada amb els castells de Marinyén i d'Alcalà" ${ }^{1}$. La donació incloïa tots els pobles, terra i gent, com era costum. A les darreries del segle tretze la vall estava poblada quasi en la seua totalitat per mudéjars. A banda de possibles raons religioses, amb l'establiment d'un monestir a la vall, el rei Jaume II pretenia atraure repobladors cristians. El monestir, com a institució, podia proporcionar direcció en aquest projecte.

El monestir ocupava una gran quantitat de territori, el qual fitava "amb els districtes de Cullera i de Corbera, d'Alzira i Barx, Barxeta i Bayrén i fins la mar i sota la mar per una milla"2 . El territori del monestir fitava amb Xàtiva a l'oest. L'extensió geogràfica de les possessions del monestir podia causar problemes des del principi. De fet, immediatament després de l'establiment del convent, Cullera es queixà al rei de que el monestir havia pres part del seu terme. Xàtiva també tingué problems similars amb el monestir de Valldigna ${ }^{3}$.

Vejam doncs, la disputa entre Xàtiva i el monestir de Valldigna, la qual data del 17 de juny de 1321, vint-i-tres anys després de la fundació del monestir. En aquesta ocasió, el conflicte era entre el justícia de Valldigna, Ramon Safont, i el lloctinent del batlle de Xàtiva, Arnau Sarranyana. El lloctinent de batlle de Xàtiva, seguint la petició de Suleima Abarrina, mudéjar de Valldigna, tenia en el seu poder Omar i Maoma Alhandacle. Aquests dos

1. A.C.A., Cancelleria, Reg. 196. folis 175r-v: "totam vallem predictam cum castris de Marinyen et de Alcalano".

2. A.C.A., Cancelleria, Reg. 196, folis 175r-v: "cum terminis de Cullera et de Corbaria, de Algezira et de Barg et de Barxeta et de Bayren et usque ad mare et infra mare per unum miliare".

3. Segons Agustí Ventura, Valldigna "pertanyia al terme general de la ciutat [=Xàtiva], com ho demostren les donacions del Repartiment, on es donen terres als qui se'ls donen cases a Xàtiva, però no al terme particular, que era el que pagava contribucions", p. 51. Vegeu Agustí VENTURA, «Les demarcacions històriques de la Xàtiva Foral», Xàtiva. Fira d'Agost (1986): 43-54.

Pel que fa als problemes entre Xàtiva i el monestir de Valldigna relacionats amb la qüestió del terme vegeu, per exemple, A.C.A., Cancelleria, Reg. 154, foli 55v entre d'altres. 
mudéjars eren de Roseta, una alqueria de Castelló de Xàtiva, avuí Castelló de la Ribera, en el terme de Xàtiva. Omar i Maoma foren acusats de furtar "aradres ab relles et altres apparellaments de laurar" en la vall".

Segons el justícia de Valldigna, Omar i Maoma havien segut "denunciats en la cort de Vayldigna per aquells als quals lo dit furt et ladronici fon ffeit" ${ }^{\prime \prime}$. Encara que els dos mudéjars eren del terme de Xàtiva, el crim havia segut comés a Valldigna i, consegüentment, a l'àrea sota la jurisdicció del monestir. El fet de que els dos mudéjars estigueren sota la jurisdicció del lloctinent de batlle de Xàtiva indica que havien tornat a Roseta o a Xàtiva després de cometre el crim. El lloctinent de batlle de Xàtiva els havia apresat i els tenia sota la seua custòdia.

El justícia de Valldigna, Ramon Safont, requerí en persona que el lloctinent de batlle de Xàtiva li lliurara els dos mudéjars acusats del crim. El justícia de Valldigna tenia una bona base legal per a la seua petició. Segons els Furs de València, la denúncia havia de determinar-se "allà on els crims són comesos o allà on la [demanda] fou començada o allà on es troben aquells que començaren la demanda" 6 . El cas complia tots aquests requisits.

El lloctinent de batlle de Xàtiva decidí ignorar aquestes raons així com d'altres. El justícia de Valldigna acusà al batlle de Xàtiva d'actuar contra els privilegis de l'abat de Valldigna. Segons el justícia de Valldigna, el rei Jaume II havia concedit mer imperi a l'abat del monestir. Consegüentment, l'abat tenia jurisdicció en causes criminals. Els registres de Jaume II demostren que en 1298 , l'abat, de fet, havia rebut el mer així com el mixt imperi ${ }^{7}$. L'abat, en consequència, tenia jurisdicció en causes criminals així com civils. Aquests drets foren inclosos també en els privilegis reials al monestir en $1300^{8}$.

El justícia de Valldigna intentà demostrar la seua demanda amb un trasllat del document de fundació del monestir. Curiosament, el justícia de Valldigna envià Suleima Abarrina amb la dita còpia al lloctinent de batlle de Xàtiva. En aquesta ocasió, el lloctinent de batlle de Xàtiva apresà Suleima per "çò com no volch los dits criminosos denunciar denant lo dit N'Arnau"9. El denunciar a Omar i Maoma a la cúria de Xàtiva del crim comés hauria complit una de les normes establertes als Furs. És a dir, el crim havia de ser jutjat allà on la causa havia començat.

4. A.H.N., Clero secular y regular, Bernardos de Valldigna, carpeta 3375, pergamí 3.

5. Ibidem.

6. Fori antiqui Valentiae, Manuel Dualde Serrano, ed., Madrid-Valencia, 1950-1967: XXXVIII, 1: "Crimina, ubi commissa vel ubi inchoata sunt vel ubi reperiuntur qui rei criminis per[h]ibentur".

7. A.C.A., Cancelleria, Reg. 196, folis 175r-v.

8. Vegeu per exemple A.C.A., Cancelleria, Reg. 198, folis 241r-242r.

9. A.H.N., Clero secular y regular, Bernardos de Valldigna, carpeta 3375, pergamí 3. 
Aquesta no fou l'única acusació contra Suleima. Un cristià de Xàtiva, Hom de Déu d'Olesa, subsegüentment denuncià Suleima "per çò car feu pendre los dits sarrahïns criminosos"10. No està clar el que açò significa. Sembla que fos un altre intent per fer que el cas es quedara a Xàtiva.

Les accions del lloctinent del batlle de Xàtiva disgustaren encara més al justícia de Valldigna. El batlle de Xàtiva tenia ara en el seu poder tres mudéjars, un d'ells de Valldigna. A més a més, el lloctinent de batlle de Xàtiva tardà molt de temps en contestar la petició del justícia de Valldigna, amb l'excusa de que havia de consultar-ho amb el batlle de Xàtiva. Quan la resposta finalment arribà, el cas es complicà d'una manera sorprenent. Suleima, encara en poder del lloctinent de batlle de Xàtiva, fou acusat una altra vegada per Hom de Déu D'Olesa. En aquesta ocasió el càrrec era molt seriós. Segons Hom de Déu, Suleima "és cristià et va en abit de moro et ha renegada la fe de Jhesucrist"11. Com en l'acusació primera, açò potser fora simplement una maniobra per a desacreditar Suleima o per a retardar el cas. De fet, Arnau Sarranyana, després de discutir l'assumpte amb el batlle de Xàtiva, adduí que no podia donar una resposta perquè estava "penden [de la] confesió del dit home qui.s diu moro" 12 .

Després de la confessió, el lloctinent del batlle de Xàtiva decretà que ell no creia que l'abat de Valldigna tenia el mer imperi en la vall. El lloctinent de batlle de Xàtiva es queixà de que el trasllat del document de fundació del monestir li havia segut presentat pel justícia de Valldigna, "solament a huyl"13. Consegüentment, el lloctinent de batlle respongué que ell no podia lliurar Suleima

"si donchs manament non avia del senyor rey o d'altre en loc d'aquell a qui la declaració o cognició dels dits privilegis se pertangués, qui expresament li manàs et de certa sciència" ${ }^{\prime 14}$.

El lloctinent de batlle adduia les mateixes raons per a Omar i Maoma. Segons el lloctinent de batlle de Xàtiva, aquests dos mudéjars eren del terme de Xàtiva i consegüentment estaven sota la seua jurisdicció. L'astut oficial de Xàtiva demanà que el transllat que havia proporcionat l'abat com a prova de que tenia el mer imperi fora registrat al llibre de la cúria

"per çò que d'aquells et del procés et de l'enantament feit sobre les dites coses puixa ésser cert a aquells a qui.s pertanga et que alcuna mutació en los dits translats no puixa ésser feita"

10. Ibidem.

11. Ibidem.

12. Ibidem.

13. Ibidem.

14. Ibidem.

15. Ibidem. 
Aquest document és l'únic que jo he trobat sobre aquest cas. No sabem com acabà el cas, encara que pensem que el justícia de Valldigna deguere apel-lar al rei, com sovint es feia en aquests casos. El que és curiós és que la disputa es centrà sobre mudéjars. En aquest cas, així com en els casos que presentaré després, solament se n'apercebim dels mudéjars perquè els incidents de la seua vida afecten als cristians.

La questió fonamental en aquest cas és la jurisdicció sobre els mudéjars. Tant el justícia de Valldigna, el qual, de fet, tenia jurisdicció en aquest cas, així com l'astut lloctinent del batlle de Xàtiva, tenien un gran interés en rebre part de la pena monetària que corresponia al crim. El rei volia controlar la justícia al regne de València, perquè hi rebia un quart de totes les penes monetàries imposades per les corts ordinàries. Aquesta suma podia ser més elevada en el cas de Xàtiva. En 1264 Jaume I ordenà als mudéjars de Cocentaina que

"en el futur no deveu respondre al nostre justícia de Cocentaina, sinó a aquell que siga el nostre batlle de Cocentaina, així que, ell escolte i determine totes les causes criminals que siguen entre vosaltres segons la vostra Suna i que aquell sarraí que siga el vostre qadi escolte totes les causes civils que siguen entre vosaltres"16.

El mateix any, aquest ordre fou aplicat també als mudéjars de Xàtiva. En aquestes dues aljames, si l'oficial reial jutjava les causes criminals, la suma que rebia el rei no estava limitada a un quart de la pena monetària. Una raó addicional, com apunta Burns, és el fet de que els oficials reials eren més justos a l'hora de jutjar els mudéjars que els justícies locals ${ }^{17}$.

Aquest document presenta un altre aspecte important; quin seria l'oficial encarregat de jutjar els dos mudéjars de Roseta a Xàtiva, així com a Valldigna? Aquesta resposta és una mica complicada. No està molt clar qui tenia la competència en causes criminals entre sarraïns a principis del segle catorze, és a dir, abans de la famosa legislació alfonsina. En el cas de Valldigna hauria segut el justícia, com a representat de l'abat. En el cas de Xàtiva, com acaben de vore, si les coses eren com al 1264, aquesta tasca requeia en mans del batlle.

L'ordre de 1264 indica que les causes criminals entre els mudéjars de Xàtiva, així com entre els mudéjars de Valldigna, havien de ser jutjades segons la seua Suna ${ }^{18}$. La questió és, com podia un oficial cristià, el qual desco-

16. A.C.A., Cancelleria, Reg. 13, foli 236r: "de cetero non teneamini de aliquibus in posse iusticie nostre Cocentaine respondere, set in posse illius qui baiulus noster Cocentaine fuerit, ita quod, ipse audiat et determinet omnes causas criminales que inter vos fuerint secundum açunam vestram et ille sarracenus qui cadit vester fuerit audiat omnes causas civiles que inter vos fuerint"

17. Robert I. BuRNs, L'Islam sota els croats, vol. I, València, 1990, p. 385.

18. Pel que fa als mudéjars de Valldigna o Alfàndec, com es deia fins 1298. vegeu A.C.A., Cancelleria, Reg. 196, folis $164 \mathrm{v}-165 \mathrm{r}$. 
neixia la llei islàmica, jutjar un mudéjar seguint aquesta? És ben possible que en ambdós casos, i com decretà la legislació alfonsina de 1329, l'oficial cristià jutjara la causa junt amb el qadi. Segons Burns, la majoria dels casos "seguien la llei, els procediments i les penes de l'islam, posades en pràctica per jutges musulmans que actuaven sota el control immediat de l'oficial cristià i en nom seu." Febrer Romaguera manté que

“también podía solicitar el señor poseedor del mero imperio la concurrencia del alcadí general del reino o de otro alcadí real, que determinase la causa contra algún vasallo moro delincuente, tal como vemos que ocurría en 1460 en Vall d'Alfàndec, donde el alcadí de Xàtiva, Yucef Alcamba, era requerido para ir al valle para juzgar a un moro asesino, a instancia del abad de Valldigna, señor de este valle"19.

De tots els personatges que apareixen al cas, el més interessant és Suleima, el qual és presentat al document simplement com a un sarraí de Valldigna. Aquesta decripció és inadequada. Suleima té un paper molt important en aquest embrollat cas. Suleima és el contacte entre les dues parts involucrades en la disputa. Un fet interessant és que el justícia de Valldigna envià a Suleima a Xàtiva amb el trasllat del document de fundació del monestir. Per tal de comunicar-se amb les autoritats cristianes, les de Valldigna, així com les de Xàtiva, Suleima necessitava parlar romanç. La qüestió del bilingüisme entre els mudéjars és important. A principis, així com a mitjan del segle catorze, com ha demostrat Boswell, la majoria dels mudéjars valencians parlaven solament l'àrab. Açò ocorria especialment a les zones rurals, on els mudéjars no tenien un contacte tan freqüent amb els cristians com aquells mudéjars que vivien a les moreries urbanes. Bé, si Suleima era un dels pocs mudéjars que parlaven romanç en aquest temps, potser que açò siga degut al fet de que era un renegat, com l'acusació deia?

De totes formes, la questió és per què actuà Suleima com a representant del justícia de Valldigna? Per què s'involucrà Suleima en el cas des del principi? Potser que Suleima ocupara una posició important a Valldigna? Segons el document, Suleima havia requerit que el lloctinent de batlle de Xàtiva tinguera presos els mudéjars acusats del crim. Segons els Furs, qualsevol habitant del regne de València podia prendre un lladre sempre que l'entregàs a la $\operatorname{cort}^{20}$. Potser que açò fos el que passà en aquest cas.

L'aspecte més interessant de Suleima, però, és el fet de que fou acusat $\mathrm{d}$ 'haver renegat la fe cristiana. Aquests casos no passaven molt sovint. La corona prengué mesures per tal de separar les tres comunitats religioses amb el fi d'evitar contaminació entre elles. Açò, en realitat, era molt difícil d'aconseguir. El contacte, fins i tot a les zones rurals, s'incrementava degut al fet de

19. Manuel FEBrer RomaguerA, «Los tribunales de los alcaídes moros en la aljamas mudéjares valencianas», Anuario de Estudios Medievales, 22 (1992): 45-78, p. 54.

20. Fori antigui Valentiae, VII, 1. 
que la presència cristiana augmentava amb el pas del temps. Seria impossible determinar la causa de la conversió de Suleima; alguns renegats eren sincers, d'altres simplement buscaven una millor oportunitat ${ }^{21}$. Més important que la raó de la conversió, però, són les conseqüències de la suposada conversió. Açò exa un crim molt fort, al qual en teoria s'aplicava la pena de mort. Segons el Furs de València, els renegats havien de ser cremats vius. No sabem què passà en el cas de Suleima. El document al-ludeix a una confessió feta per Suleima, però no explica res més. Fins i tot, en cas de que Suleima fora culpable, no és segur que l'hagueren cremat. En realitat, la majoria dels culpables es lliuraven de la pena de mort de diferent maneres: amb exili, perdons reials, etc.

El segon grup de documents, que provenen de l'Arxiu de la Seu de Xàtiva, ens mostra també diversos punts de contacte entre cristians i mudéjars del terme de Xàtiva. En aquest cas els personatges involucrats en els documents són mudéjars de Beniatjar, en el terme de Carbonera. Aquesta àrea pertanyia al terme de Xàtiva. En la Vall d'Albaida, les alqueries, seguint el costum del temps musulmà "estaven agrupades pel castell que les defenia", en aquest cas el de Carbonera ${ }^{22}$. El castell de Xàtiva exercia jurisdicció sobre aquest castell així com els castells de Lutxent i Vilella, Rugat, Albaida i Ontinyent ${ }^{23}$.

Aquests quatre documents, recentment catalogats, ens detallen, sense voler, algunes de les activitats financeres de quatre mudéjars de Beniatjar: el préstec de diners d'un cristià de Xàtiva i la venda i transmissió de propietat entre mudéjars. Els quatre documents ens detallen un període d'onze anys, de 1334 a 1345. Aquests quatre mudéjars, Çaat i Rida Abenrrida, Hudeill aben Hudeill i Ali Amfagall apareixen repetidament als quatre documents una vegada com a testimonis, una altra com a compradors o venedors.

L'altre aspecte curiós és que tots quatre mudéjars de Beniatjar anaren a Xàtiva durant aquest període de temps i establiren un contracte legal amb el mateix cristià de Xàtiva: Pere de Blancafort. Qui era, doncs, Pere de Blancafort, i quina era la seua relació amb Beniatjar? Aquest personatge apareix repetides vegades als pergamins del segle catorze de l'arxiu de la Seu de Xàtiva. La majoria dels documents presenten a Pere de Blancafort rebent pagament de deutes d'algun cristià de Xàtiva. En dues ocasions, Pere de Blancafort apareix relacionat amb la comunitat jueva de Xàtiva, com ara en 1328, quan Astruc Abeç, jueu de Xàtiva, absolgué a Pere de Blancafort d'una suma de diners ${ }^{24}$. Potser que Blancafort fora un prestamista. Pere de

21. Maria Teresa Ferrer I MALLOL, Els sarraïns de la corona catalano-aragonesa en el segle XIV. Segregació i discriminació, Barcelona, 1987, pp. 77-83.

22. Agustí VEntuRA, «Les demarcacions històriques de la Xátiva Foral», Xátiva. Fira d'Agost (1986): 43-54, p. 51.

23. Ibidem, p. 51.

24. Arxiu de la Seu de Xátiva (A.S.X.), pergamí 11. 
Blancafort sembla haver acumulat una bona riquesa a consequència de les seues activitats financeres. El 1324, Guillem Carbó, vehí de Xàtiva, donà tota la propietat que Domènec Carbó tenia a Beniatjar, a Pere de Blancafort ${ }^{25}$. Potser que açò fora per pagar un deute a Blancafort. Potser que aquest document explique la raó de la presència d'aquest cristià a la vida dels mudéjars de Beniatjar.

Vejam, doncs, el contingut d'aquests quatre documents. El primer pergamí data de 1334. En aquesta ocasió, Çaat i Rida Aberrida, mudéjars de Beniatjar, firmaren un document en presència del notari públic de Xàtiva, Pere de la Raga, en el qual confessaven deure a Pere de Blancafort, present, setanta sous que Pere els havia prestat. El segon document involucrant Pere de Blancafort i alguns mudéjars de Beniatjar data de 1338. En aquesta ocasió, Hudeill aben Hudeill, mudéjar de Beniatjar, venia a Ali Amfagall, també mudéjar de Beniatjar, "la meitat de tota aquella heretat de terra erma i treballada la qual vaig adquirir de Pere de Blancafort en el terme del dit lloc així com la tinc i posseisc amb la meitat de les cases de la dita heretat ${ }^{\prime 26}$. No sabem quan Hudeill aben Hudeill havia adquirit la propietat de Pere de Blancafort. Es possible que l'havia adquirida en 1328, quan Blancafort rebé la propietat de Domènec Carbó a Beniatjar.

Hudeill aben Hudeill prometia entregar a Ali Amfagall la propietat tan prompte com Amfagall i la seua dona, o el seu fill i la seua dona, ocuparen les cases en questió. Sembla que Ali Amfagall no intentava mudar-se a les cases immediatament. Segons l'escriptura de compra-venda, Hudeill aben Hudeill establia que "pel que fa a la meitat de les cases promet donar-vos en concepte de lloger d'aquesta [meitat] sis sous i huit dinars a l'any mentre jo les tinga" 27 . El document detalla que la renda censal que Hudeill aben Hudeill pagava a Pere de Blancafort pel total de la propietat era de "cent tretze sous $\mathrm{i}$ quatre dinars i una càrrega de llenya i un parell de gallines" 28 . Amb la venda de la meitat de la propietat, la renda que s'havia de pagar a Pere de Blancafort es partia per la meitat entre Hudeill aben Hudeill i Ali Amfagall.

Sis anys després, en 1344, la mateixa meitat de terra i de cases que Hudeill aben Hudeill havia venut a Ali Amfagall fou venuda per aquest a Çaat Aberrida, mudéjar de Beniatjar, com hem vist abans. La mateixa renda

25. A.S.X., pergamí 26.

26. A.S.X., pergamí 27: "medietatem tocius illius hereditatis terre hereme et laborate et olivaria quam adquisivi a Petro de Blancafort in termino dicti loci prout ego teneo et possideo cum medietate domorum dicte hereditatis".

27. A.S.X., pergamí 27: "de qua medietate domorum promitto vobis dare pro logerio ipsius quolibet anno sex solidos et octo denarios dum ego ipsas tenuero".

28. A.S.X., pergamí 27: "C et XIII solidorum et IIII denariorum et unius honeris lignis [=ligni] et unius paris gallinarum". 
censal s'aplicava en aquest cas. Un any després de comprar aquesta heretat, en 1345, Çaat Abarrida es trobà una altra vegada davant d'un notari cristià i de Pere de Blancafort. En aquesta ocasió Çaat reconeixia que li devia a Blancafort cent setanta-tres sous reials de València i mig, "és a dir, norantasis sous i mig" els quals Pere de Blancafort li havia prestat per tal de comprar una mula, i setanta-set sous que li devia de renda censal per aquella propietat "la qual jo tinc per tu a un terç de la renda en el terme del dit lloc de Beniatjar i la qual jo us devia del temps passat fins a la festa de la quaresma pròxima passada" 29 . Aquesta renda sembla indicar que Çaat tenia una altra propietat de Pere de Blancafort a cens.

Com en el cas dels mudéjars de Roseta acusats de robar relles a Valldigna, els quatre documents de l'arxiu de la Seu de Xàtiva ens proporcionen unes imatges esporàdiques de la vida de quatre mudéjars d'un altre lloc del terme de Xàtiva, Beniatjar, així com el contacte que aquests mudéjars tenien amb la comunitat cristiana, la qual s'incrementava en nombre. Un exemple clar d'aquest fenomen és el fet de que la propietat que Hudeill aben Hudeill vengué a Ali Amfagall, la qual aquest vengué després a Çaat, és descrita de la manera següent:

"així com fit[a] amb la terra d'Udeyll Abenudell sarraí i amb la terra d'En Salzeda i de Miguel Muñoz; i les cases són afrontades per les cases d'Alfonso Martínez i per la terra de Miguel Muñoz i per la via pública ja nomenada" ${ }^{\prime 30}$.

Aquests pergamins ens il-lustren també quines eren les condicions de treball i propietat de la terra dels mudéjars. En aquest cas els mudéjars eren propietaris-arrendataris de la terra i de les cases. No sabem quines raons tenia Hudeill aben Hudeill per a vendre la meitat de la propietat a Ali Amfagall. Hudeill aben Hudeill, així com Ali Amfagall, venien la propietat que tenien sota domini directe de Pere de Blancafort. Consegüentment, no s'establia entre ells ninguna relació de tipus feudal. El mudéjar que venia la propietat i el que la comprava simplement es partien la renda a pagar a Pere de Blancafort, la qual entregaven directament i per separat al cristià de Xàtiva. Segons Burns,

"igual que els cristians, els mudéjars del regne de València havien de satisfer un dret d'entrada quan adquirien terra nova, i un impost sobre les vendes quan es desprenien de llurs terres" ${ }^{\prime 31}$.

29. A.S.X., pergamí 94: "videlicet nonaginta sex solidos et dimidium"; "quam pro vobis [habeo] ad tercium censum in termino dicti loci de Beniatjar et quod censum vobis debebam de tempore transacto usque ad festum carnisprivii proximi transacti"

30. A.S.X., pergamí 138: "prout affrontar cum terra de Udeyll Abenudell sarraceni et cum terra d'En Salzeda et Michaelis Munyoç; et domos confrontantur cum domibus Alfonsi Martiniç et cum terra Michaelis Munyoç et cum via publica iamdictam".

31. Robert 1. BurNs, Colonialisme medieval, València, 1987, p. 164. 
Ali Amfagall pagà a Hudeill aben Hudeill cinquanta sous reials de València quan adquirí la propietat. Ali Amfagall vengué la propietat a Çaat Abarrida per quaranta-cinc sous reials de València lliures de lluïsme. El lluïsme, o impost sobre la venda, es pagava al senyor que tenia el domini directe de la terra, en aquest cas Pere de Blancafort. Segons el contracte entre els mudéjars, el comprador podia vendre, alienar, donar, etc. la propietat "llevat del dit cens, dret, domini, lluïsme i fadiga al dit Pere de Blancafort" ${ }^{\prime 32}$.

El domini de la terra estava en mans d'un cristià absentista. Açò explica el fet de que els mudéjars de Beniatjar hagueren d'anar a Xàtiva a ocupar-se dels negocis relacionats amb la propietat i les rendes. Potser foren les rendes les que més facilitaven el contacte entre les comunitats cristiana i mudéjar. En aquest cas, els mudéjars de Beniatjar havien d'entregar a Pere de Blancafort la renda, la qual estava dividida en tres terminis: un a pagar en la quaresma, un altre a pagar en juliol i l'últim a pagar en Nadal. La primera i la darrera són dates significatives al calendari cristià. Açò és un exemple més de com el pensament cristià s'anava imposant d'una manera directa o indirecta en la vida i la mentalitat dels mudéjars.

Pel que fa a la manera de treballar la terra, en aquest cas sembla que açò era fet pel mateix propietari-arrendatari, el qual normalment residia a la propietat. Al pergamí 27, en el qual Hudeill aben Hudeill vengué la meitat de l'heretat a Ali Amfagall, sembla que Ali Amfagall planejava treballar la terra sense ocupar immediatament les cases que comprava d'Hudeill aben Hudeill. Pel que fa a Hudeill aben Hudeill, sembla que ell residia a la propietat $i$ a les cases que en ella hi havia.

Un altre aspecte important en aquestes transaccions és el fet de que els mudéjars acudiren a un notari cristià per tal de redactar una escriptura de compra-venda que es feia entre dos mudéjars. La raó òbvia d'açò és el fet de que la propietat estava sota el domini directe d'un cristià. Els documents segueixen els cànons cristians. El contracte s'establia segons la llei cristiana. En el cas dels préstecs, Çaat Aberrida renuncià "pel que fa a açò a tota la Sunna i Sharia dels sarrains" 33 . La forma de vida i les normes cristianes anaven sobrepassant les formes islàmiques ${ }^{34}$.

Les escriptures de compra-venda i els préstecs, com el paper de Suleima en la disputa de jurisdicció entre Xàtiva i Valldigna, apunten al tema

32. A.S.X., pergamí 27: "salvo tamen dicto Petro de Blancafort dicto censu, iure, dominio, laudimio et fatica".

33. A.S.X., pergamí 94: "quantum ad hoc omni çune et xare sarracenorum".

34. Un altre aspecte interessant és que a tots aquest documents davant d'un notari cristià públic de Xátiva, hi ha testimonis cristians i mudéjars. Segons els Furs de València, els notaris havien d'incloure als documents dos o tres testimonis. No sé si hi havia una norma específica per que fa al nombre de testimonis i a la seua religió en els documents entre cristians i mudéjars. El nombre de testimonis en aquest documents varia: de dos cristians i un mudéjar, a un cristià i dos mudéjars, a un cristià i un mudéjar. 
del bilingüisme entre els mudéjars valencians. Si és veritat que la majoria dels mudéjars valencians tan sols parlaven l'àrab, com s'entenien, doncs, amb els seus senyors cristians? En la venda feta per Hudeill aben Hudeill a Ali Amfagall i la feta per aquest últim a Çaat Aberrida, n'hi havia un altre document redactat en àrab? Segons Febrer Romaguera,

"con la aculturación creciente de la comunidad mudéjar valenciana, los moros fueron requiriendo progresivamente la presencia de los notarios cristianos en sus relaciones con los cristianos, aunque conservaron a sus alfaquíes para la redacción de los documentos más típicamente de la esfera privada, referente a la familia y propiedad, que afectaban sólo a moros" ${ }^{\prime 35}$.

En aquests casos, una altra raó és que els contractes escrits en àrab davant d'un faquí no tenien valor a les corts cristianes, a no ser que foren traduits ${ }^{36}$.

Siga com siga, el que els documents escrits per cristians presentats ací ens demostren és que, durant la primera meitat del segle catorze, les zones rurals del terme de Xàtiva, on la majoria de la població era mudéjar, no estaven lliures de la influència cristiana. De fet, conforme el contacte amb la població cristiana s'incrementava, el contacte amb la justícia cristiana i amb els oficials cristians també augmentava. Aquests documents que han sobreviscut de manera fortuïta proporcionen veu a una minoria sotmesa que d'altra manera seria muda. Aquesta documentació també il-lustra com, des del punt de vista dels cristians valencians, els mudéjars de la primera meitat del segle catorze constituien un grup valiós i una important font d'ingressos.

$* * *$

\section{APENNDIX DOCUMENTAL}

\section{A. Archivo Histórico Nacional.}

Clero secular y regular. Bernardos de Valldigna, carpeta 3375, pergamino 3.17 de juny de 1321.

Quinto kalendas iulii, anno Domini millesimo trescentesimo vicesimo primo. Comparech davant N'Arnau Sarranyana, tinentloc de l'honrat En Pere Ffuster, batle de Xativa, En Ramon Çafont, justícia qui-s dehia de Vaildigna, et en presència dels testimonis deiús escrits per mi, Bernat de Morella, notari publich del dit loch de Xàtiva legir feu et publicar a aquell l'escrivania que.s segueix: Constituit En Ramon Sa Font, justícia de Vaildigna, denant la presència d'En Arnau de Sarranyana, tinentloc segons que.s diu de l'honrat En Pere Ffuster, batle de Xàtiva, dix et proposa que com ell, dit N'Arnau, a requi-

35. Manuel FEBRER ROMAGUERA, «Los tribunales de los alcadíes...», p. 62.

36. Asunción BLASCO MARTíneZ, "Notarios mudéjares de Aragón (siglos XIV-XV)», en Homenaje a la Profesora Emérita María Luisa Ledesma Rubio, Zaragoza, 1993: 109-133, p. 113. 
sició de Çuleyma Abarrina, sarray de Vaildigna, haia et tinga presos en son poder Omar et Mahomet Alhandacle, sarrayns qui-s diu ésser de Roseta per rahon de furt et ladronici $\backslash$ que perpetraren en la dita vayl furtan et fahen furt et ladronici/ d'aradres ab relles et altres apparellaments de laurar. Del qual ffurt et ladronici ssón denunciats en la cort de Vayldigna per aquells als quals lo dit furt et ladronici fon ffeit et lo dit justícia aja request de paraula al dit $N^{\prime}$ Arnau que.ls dits sarrahïns denunciats li deia liurar presos et recaptats per tal que d'aquells puixa fer compliment de dret et de justícia en aquell loch on lo dit crim fon per aquells perpetrat segons que per Fur es fahedor, majorment com en lo dit loc del dit crim sien denunciats.

E lo dit N'Arnau diga que sobre açò haura son acort; per çò lo dit En Ramon Çafont, $a b$ aquest escrit, requer $a b$ tanta instància quanta pot que.ls dits denunciats li deliure presos et recaptats per çò que d'aquells puixa fer compliment de justícia là on dit crim et furt et ladronici ffeeren et perpetraren et $\mathrm{d}^{\prime}$ aquell foren denunciats.

En altra manera protesta que.l dit N’Arnau contra rahó bona agreujara lo dit justícia et la juridicció de don abbat de Vaildigna, lo qual ha plenera juridicció et merinperi en la dita vail, et ffarà et vendrà contra lo privilegi per lo senyor rey atorgat al dit don abbat et als habitants en aquella vail; translat del qual privilegi lo dit N'Arnau té en son poder que en aquest dia li fon liurat per Çuleyma Abarrina, sarrahí; lo qual sarrahí segons que-s diu lo dit $N^{\prime}$ Arnau pres per çò com no volch los dits criminosos denunciar denant lo dit $N^{\prime}$ Arnau. Et aprés, segons que.s diu, ten aquell pres en son poder per tractament d'En Hom de Déu d'Aulesa, qui.s diu que l'ha denunciat per çò car feu pendre los dits sarrahïns criminosos. Lo qual Çuleyma axí mateix requer lo dit justícia que li sia liurat com ell sia apparellat de tenir-lo a dret et fer d'aquell compliment de justícia, com sia de la sua juridicció del dit N'Arnau.

Et si alcuna de les dites coses lo dit $N^{\prime}$ Arnau li contrastara, protesta lo dit justícia contra lo dit $\mathrm{N}^{\prime}$ Arnau et sos bens, axí com contra aquell qui vendria et faria contra los privilegis atorgats a don abbat et a la dita vayl. E protesta que en fadiga del dit $N^{\prime}$ Arnau, haura arretorero a major qui 1 proveesca de dret et de rahon et punisca lo dit N'Arnau del seu delinquiment et de tots dans, messions et interés que per aquesta rahon convenga fer ho sostenir al dit justícia o a don abbat de Vayldigna o al dit Çuleyma. Et requer que la present escriptura li sia mesa en forma pública per lo notari deiús escrit a consservació del dret del dit don abbat et dels habitants en la dita vaill. Et lestes les dites coses, ho escriptura per $\mathrm{mi}$, dit notari, al dit tinentloc de batle; encontinent lo dit loctinent dix que auria son acort sobre.l dit ffeit et aprés que·n faria çò que degués.

Testimonis foren a les dites coses presents En Jacme Tolrrà, notari, N'Arnau d'Aviu et En Hom de Déu d'Aulesa, vehïns de Xàtiva, et En Pere Calçada, notari d'Algezira.

Et en aprés en lo dit dia, aprés d'un poch estat, lo dit loctinent de batle, haut lo dit acort, feu la resposta davail següent en presència del dit En Ramon Çafont et dels testimonis deiús escrits et lo dit N'Arnau de Sarranyana, loctinent de batle, que desús diu que lo dit En Hom de Déu avia denunciat lo dit hom qui-s appella Çuleyma, davant lo dit loctinent de molt fort crim, çò és que aquell qui.s diu Çuleyma és cristià et va en abit de moro et ha renegada la fe de Jhesucrist, segons que en la denunciació d'aquen feita appareix; per rahon de la qual denunciació lo dit loctinent de batle enanta a penden confesió del dit home qui.s diu moro sobre lo crim del qual aquell és estat denunciat.

Aprés la qual conffesió ffeita, lo dit En Ramon Çaffont, qui.s diu justícia de Vayldigna, proposa la dita escriptura o requisició. Et com al dit loctinent de batle no sia cert lo dit don abat ni el dit En Ramon Çaffont aver merinperi en la dita Vayldigna segons que per aquell és estat proposat ne açò bonament se mostre per los transllats, que.s dien ésser treits de privilegis atorgats al dit orde, los quals aquell En Ramon ha demostrat solament a huyl, çò és que.1 dit abat ni l'orde d'aquell aien lo dit merinperi et là on fos vist et 
declarat per aquell a qui-s pertany que per los dits privilegis fos atorgat merinperi als desús dits, çò que no appar. Encara no.s mostraria ne seria cert al dit loctinent aquells aver usat del dit merinperi. Em per açò diu lo dit loctinent de batle que ell bonament no pot ni deu deliurar lo dit hom qui.s appella Çuleyma al dit En Ramon Çaffont, perquè aquell no li deliuraria si donchs manament non avia del senyor rey o d'altre en loc d'aquell a qui la declaració o cognició dels dits privilegis se pertangués, qui expresament li manàs et de certa sciència que aquell li fos deliurat ho de les coses desús dites no li era cert. Et diu encara lo dit loctinent de batle que ell no és tengut de deliurar al dit En Ramon los dits Homar et Mahomat Alfandaqui com aquells sien habitadors en Roseta, terme de Xàtiva, segons que per lo dit En Ramon és atorgat, et sien sots iurisdicció et destret de la batlia de Xàtiva, et encara per les rahons desús dites, maiorment com al dit loctinent no sia cert de les coses per lo dit En Ramon Çaffont proposades per escrit, per la qual cosa, ell no deliuraria los dits moros al dit En Ramon.

Diu encara et requer lo dit loctinent de batle al dit En Ramon que meta et pos ho faça escriure los dits translats, qui-s dien ésser treits dels dits privilegis, en lo libre de la batlia per çò que d'aquells et del procés et de l'enantament feit sobre les dites coses puixa ésser cert a aquells a qui.s pertanga et que alcuna mutació en los dits translats no puixa ésser feita.

En altra manera protesta lo dit loctinent que alcuna cosa requesta ni protestada per la part adversa no obtenga alcuna ffermetat. Les quals coses lo dit loctinent de batle requés a mi, dit notari, que li continuàs aprés la dita escriptura per lo dit En Ramon Çaffont proposada per resposta d'aquella. Et encontinent lo dit En Ramon Çaffont diu que ell no ffaria registrar los dits translats en lo libre de la batlia, mes si lo dit loctinent los hia mester que.ls hi faça metre et perseveran en ço que desús dit ha proposat et protestat, requer que totes les coses li sien liurades en forma pública. Et lo dit loctinent de batle persevera en la dita resposta, rahons et prestació per ell desús feites, les quals totes sengles coses foren lestes et publicades per mi, dit notari, en Exàtiva, en lo dia et any damunt escrits.

Testimonis foren a les dites coses presents los dits En Jacme Tolrrà, notari, Arnau d'Aviu et En Hom de Déu d'Aulesa, vehïns de Xàtiva et En Pere Calçada, notari d'Algezira.

Sig+num Bernardi de Morella, notarii publici Xative, qui hoc scripsit cum superposito in linea IIII, ubi dicitur que perpetraren en la dita vail furtan et fahen furt et ladronici, et cum raso et emendacio in eadem linea ubi scribitur són denunciats et clausit loco, die et anno prefixis.

\section{B. Arxiu de la Seu de Xàtiva.}

Carpeta 1, pergamí 154. 8 de febrer de (1333) 1334.

Sit omnibus notum quod nos Çaat Aberrida et Rida Aberrida sarraceni de Beniatjar ambo insimul et uterque nostrum in solidum, scienter per nos et nostros confitemur et in veritate recognoscimus nos debere vobis, Petro de Blancafort, vicino Xative presenti et recipienti et vestris et quibus volueritis septuaginta solidos regalium quos in denariis numerando nobis mutuastis. Renunciantes omni excepcioni mutui predicti a nobis non recepti et pecunie predicte vobis non debite et doli.

Quos quidem septuaginta solidos regalium promittimus et bona fide convenimus vobis et vestris solvere et cui volueritis ad vestram voluntatem statim et in continenti cum a vobis vel ab aliquo loco vestri inde fuerimus moniti seu requisiti sine omni dilacione, excusacione et deffensione, querela sive dampno, gravamine et missione vestri et vestrorum ac omni etiam interesse. Et si pro hiis denariis petendis seu recuperandis dampnum ali- 
quod habueritis aut missiones aliquas feceritis totum illud vobis et vestris integre restituere et emendare promittimus ad vestram voluntatem.

De quibus credamini nostro plano et simplici uerbo sine testibus et iuramento obligantes ad hoc vobis et vestris uterque nostrum in solidum nos et omnia bona nostra mobilia et immobilia ubique habita et habenda.

Quod est actum Xative, VI idus februarii, anno Domini MCCCXXX tercio.

Sig+num Çaat Aberrida,

Sig+num Rida Aberrida, sarracenorum predictorum qui hoc concedimus et firmamus.

Testes inde sunt Petrus Giçbert, Jacobus Bosch et Aly Alcadus.

Sig+num Petri de la Raga, notarii publici Xative qui hoc scripsit et clasuit loco, die et anno prefixis cum raso et emendacio in xiiii linea ubi dicitur ubique.

Carpeta 1, pergamí 27. 2 de desembre de 1338.

Sit omnibus notum quod ego Hudeill aben Hudeill, sarracenus de Beniatjar, scienter per me et meos vendo, trado et concedo vobis Aly Amfagal, sarraceno dicti loci presenti et recipienti et vestris imperpetuum medietatem tocius illius hereditatis terre hereme et laborate et olivaria quam adquisivi a Petro de Blancafort in termino dicti loci prout ego teneo et possideo cum medietate domorum dicte hereditatis. Quam medietatem vobis dare et deliberare promitto in continenti cum vos cum uxore vestra steteritis in dictis domibus vel filius vester cum uxore sua.

De qua medietate domorum promitto vobis dare pro logerio ipsius quolibet anno sex solidos et octo denarios dum ego ipsas tenuero et quam terram et domos teneo ad censum $\backslash C$ et XIII solidos et IIII denarios et unum honus lignis [=ligni] et unum par ${ }^{37}$ gallinarum de quo censu teneamini solvere/ quinquaginta sex solidorum et octo denariorum regalium Petro de Blancafort annuatim solvendorum medietatem in festo carnisprivium ${ }^{38}$ quadragesime et aliam medietatem in mense iulii et medium honus lignis [=ligni] et unam gallinam in festo natalis Domini, prout affrontant cum terra mihi remanente et cum terra d'En Salzeda et Michelis Monyoç et domos cum parte mihi remanente.

Predictam itaque medietatem dicte terre et domos cum introitibus, exitibus, affrontacionibus, melioramentis et omni iure et suis pertineciis universis vobis et vestris vendo et concedo imperpetuum ad habendum, tenendum, possidendum, expletandum et ad dandum, vendendum, excommutandum, impignorandum, alienandum et ad omnes vestras et vestrorum voluntates perpetuo faciendas exceptis clericis et personis religiosis. Salvo tamen dicto Petro de Blancafort dicto censu, iure, dominio, laudimio et faticca ad forum Valencie pro precio sciliçet quinquaginta solidorum regalium quos a vobis habui et recepi. Renunciando omni excepcioni non numerati et non recepti dicti precii et doli et excepcioni minoris precii et duplicis decepcionis et illi legi que subvenit deceptis ultra dimidiam partem iusti precii et omni alii iure, foro, legi racioni constitucioni et consuetudini, beneficio et auxilio obviam venientibus. Insuper promitto vobis et vestris meam dictam vendicionem salvare et defendere et facere, habere, tenere contra omnes personas et teneri de eviccione et ab omni dampno et interesse, obligando ad hoc vobis et vestris me et omnia bona mea mobilia et inmobilia ubique habita et habenda.

Quod est actum Xative, IIII nonas decembris anno Domini MCCCXXXVIII.

37. Sic.

38. Sic. 
Sig+num Hudeill aben Hudeill sarraceni predicti qui hoc concedo et firmo.

Sig+num Petri de Blancafort domini huius rei qui recepto laudimio hanc vendicionem firmo, salvo iure meo in omnibus secundum forum Valencie.

Testes inde sunt Dominicus Barbera, Alamanus de Xea... et Cait Abarrida et firmum predicti Petri de Blancafort qui firmavit XIIII kalendas aprilis anno Domini MCCCXXXIX, Raimundi Colom et Raimundi Serra vicini Xative.

Sig+num Petri de la Raga notarii publici Xative qui hoc scripsit et clausit loco, die et anno prefixis cum superposito in VII linea ubi dicitur C et XIII et IIII et unum honus lignis [=ligni] et unum par [sic] gallinarum de quo censu teneamini solvere.

\section{Carpeta 1, pergamí 138. 23 d'octubre de 1344.}

Sit omnibus notum quod ego Ali Amfagall sarracenus de Beniajar, scienter per me et meos vendo, trado, quasi trado et concedo vobis Ç[aat] Aberrida, sarraceno dicti loci presenti et recipienti et vestris imperpetuum medietatem illius hereditamenti heremi et populati cum arboribus ibidem existentibus simul et domibus.

Quam medietatem seu hereditatem Udeyll, sarracenus dicti loci, acquisivit a venerabili Petro de Blanchaforte in termino dicti loci quamque teneo sub dominio dicti Petri ad censum quinquaginta sex solidorum et octo denariorum regalium Valencie et medii honus [=honeris] ligne [=ligni] et unius galline solvendorum annuatim medietatem in festo carniprivii quadragesime et aliam in mense iulii et dictum medium honus et dictam gallinam in festo natalis Domini et ad laudimium et faticham secundum accapiti instrumentum prout affrontat cum terra de Udeyll Abenudell sarraceni, et cum terra d'En Salzeda et Michaelis Munyoç; et domos confrontantur cum domibus Alfonsi Martiniç et cum terra Michaelis Munyoç et cum via publica iamdictam.

Ita quod medietatem dicti hereditamenti prout superius confrontatur cum introitibus, exitibus, affrontacionibus et suis omnibus pertinenciis et melioramentis universis sic vobis et vestris vendo et concedo imperpetuum precio videlicet quadraginta quinque solidorum franquorum de laudimio regalium Valencie.

Unde sum bene paccatus ad totam meam voluntatem, renunciando scienter omni excepcioni vendicionis predicte pro me vobis non facte ac pecunie predicte inde a vobis non [habite] et doli; et beneficio minoris precii et duplicis decepcionis et legi illi que subvenit deceptis ultra dimidiam partem iusti precii et omni alii iuri [constitucioni et consuetudini].

Dans et concedens vobis et vestris perpetuo quicquid hanc vend[icione]m predictam amplius modo valet vel valebit decetero precio antedicto. Et sic vos et ves[tros] [succe]sores habeatis predictam vendicionem cum omni suo melioramento [fa]ciendo teneatis, possideatis et imperpetuo expletetis ad dandum, vend[endum], [ali]enandum, obligandum, inpignorandum, excommutandum et ...ris alienandum et ad omnes vestras et vestrorum voluntates, inde cui et qui[bus] [volueritis] [in] perpetuo faciendas exceptis clericis et personis religiosis sicut melius plenius, sanius et utilius potest dici, intelligi ad vestrum et vestrorum commodum [et bonum intellectum] \salvo tamen dicto Petro et suis dicto censu et iure, in omnibus / promittens et bona fide conveniens predictam vendicionem cum omni suo melioramento facto et faciendo vobis et vestris perpetuo defendere, [sal]vare et facere, habere, tenere et possidere quiete potenter et in sana pace contra omnes personas conquerentes vel aliquid perturbantes ad forum Valencie. Et cum ... de inde vobis et vestris perpetuo de firma et legali eviccione et de omni dampno ac eciam interesse, obligando ad hoc vobis et vestris me et omnia bona mea mob[ilia] et inmobilia ubique habita et habenda.

Quod est actum Xative, decem kalendas novembris anno Domini millesimo CCC quadragesimo quarto. 
Sig+num Ali Amfagall venditoris predicti qui hoc concedo et firmo.

Sig+num Petri de Blancafort ... directi dominii huius rei qui recepto inde laudimio, hanc vendicionem fir[mo], [salvo] [c]ensu et iure meo in omnibus.

Testes huius rei sunt Guillemus Ca Rovira, vicinus Xative, et Ali Alcadi, sarracenus de Beniajar.

Sig+num Petri de Calciata, notarii publici Xative, qui hoc scripsit cum superposito in XIIII linea ubi dicitur salvo dicto Petro et suis dicto censu et iure suo ... [et] cum superposito in XV linia ubi dicitur omnibus et clausit.

Carpeta 1, pergamí 94.8 de març de 1345.

Noverint universi quod ego Çaat Abarrida sarracenus de Beniatjar, termino de Carbonera, scienter per me et meos confiteor et in veritate recognoscho me debere vobis Petro de Blancaffort, vicino Xative presenti et recipienti et vestris centum septuaginta et tres solidos et dimidium regalium Valencie; videlicet nonaginta sex solidos et dimidium quos mihi amicabiliter mutuastis in denariis ad emendum quandam mulam et septuaginta septem solidos quos vobis debebam racione census illius hereditatis quam pro vobis [habeo] ad tercium censum in termino dicti loci de Beniatjar et quod censum vobis debebam de tempore transacto usque ad festum carnisprivii proximi transacti. Renunciando scienter omni excepcioni pecunie predicte vobis non debite ut predicitur et doli.

Quos quidem CLXXIII solidos et dimidium dicte monete promitto et fide bona convenio vobis et vestris dare et solvere in continenti et statim quando inde a vobis seu ab aliquo loco vestri inde monitus seu requisitus fuero, omnibus dilacionibus, excusacionibus et deffensionibus quibuslibet pretermissis. Ita quod si forte predicto debito nostro petendo seu recuperando dampnum aliquod habueritis vel missiones aliquas seu expensas feceritis vel sustinueritis, totum illud quantumcumque sit vel fuerit vobis et vestris restituere promitto et emendare voluntati vestre; super quibus credamini vestro [=nostro] plano et simplici verbo sine testibus et iuramento obligando ad hoc vobis et vestris me et omnia bona mea ubique presentia et futura [et] renuncians quantum ad hoc omni çune et xare sarracenorum.

Quod est actum Xative, octavo idus marcii anno Domini millesimo CCCXL quinto.

Sig+num Çaat Abenrrida, sarraceni predicti qui hoc concedo et firmo.

Testes inde sunt Dominicus Argent vicinus Xative et Mahomet Axichxuch et Hamet Mazarell sarraceni Xative.

Sig+num mei Andree Cabrera notarii publici Xative qui hoc scripsit et clausit loco, die et anno prefixis.

\section{RESUM}

L'aljama de mudéjars de Xàtiva deixà constància de la seua existència mitjançant els documents redactats pels cristians. Les limitacions d'aquesta font documental són ben conegudes pels historiadors; els mudéjars són representats d'una forma distorsionada pels seus conqueridors, els cristians. Malgrat açò, la veu de la minoria conquerida es deixa sentir als documents cristians. El cas dels mudéjars de Xàtiva és especial. La documentació existent a Xàtiva desaparegué el 1707, quan Felip Vè cremà la ciutat. Consegüentment, ningú no se n'ha ocupat de cercar la documentació sobre 
els mudéjars de Xàtiva a altres arxius. Si les històries d'aljames individuals són fonamentals per a un millor enteniment dels mudéjars valencians, la història de l'aljama de Xàtiva és essencial degut a que a Xàtiva vivia la major concentració de mudéjars del regne de València.

Per tal de recuperar la història d'aquesta aljama, és essencial consultar totes les fonts documentals a les quals la veu dels mudéjars se sent directament o indirecta. El que presentem ací és documentació provinent de l'Arxiu de la Seu de Xàtiva, recentment catalogat, i de l'Archivo Histórico Nacional. Un total de cinc documents que daten de la primera meitat del segle catorze ens proporcionen informació sobre la situació econòmica dels mudéjars del terme de Xàtiva, el seu contacte amb els cristians a nivell econòmic i legal, el bilingüisme entre els mudéjars, etc.

El primer document presentat prové de l'Archivo Histórico Nacional. Aquest document presenta una disputa entre el monestir cistercenc de Valldigna i la batllia de Xàtiva sobre qui té la jurisdicció criminal sobre dos mudéjars de Roseta, alqueria del terme de Xàtiva, acusats de cometre un crim a Valldigna. El que sembla una simple disputa sobre jurisdicció criminal a fi de rebre part de la pena monetària, es complica degut a que un sarraí de Valldigna, el qual actuà com a intermediari entre Xàtiva i Valldigna, fou acusat de ser renegat. A més a més, el document suggereix altres qüestions importants com qui era l'oficial encarregat de jutjar els casos entre els mudéjars; el pes que l'increment de la presència cristiana tenia sobre els mudéjars al regne de València, especialment a les zones rurals, on el contacte amb els cristians era menys freqüent que a les aljames urbanes, etc.

El segon grup de documents, provenents de l'Arxiu de la Seu de Xàtiva, ens presenta els contractes legals de cinc mudéjars de Beniatjar, al terme de Xàtiva, i un cristià d'aquesta ciutat. Els mudéjars conreen terres sota el domini directe del cristià de Xàtiva. A més a més de les condicions de treball i propietat de la terra, aquests pergamins ens demostren, com al cas anterior, que els mudéjars de les zones rurals en aquests moments no podien escapar de la influència cristiana. Per exemple, per a redactar l'escriptura de compravenda entre dos mudéjars de la meitat de la propietat en qüestió, els mudéjars acudiren a un notari cristià.

\section{SUMMARY}

The aljama of Mudejars of Xàtiva left evidence of its existence in the documents written by Christians. The limitations of this source are well known to historians; Mudejars are portrayed in a distorted fashion by their conquerors, the Christians. Despite this, the voice of the conquered minority can be heard in the Christian documents. The Mudejars of Xàtiva are a special case. The documents that existed in Xàtiva disappeared in 1707 when Philip V 
burned the city. Consequently, no one has undertaken the search for documents in other archives. If a history of individual aljamas is important for a better understanding of Valencian Mudejars, a history of the aljama of Xàtiva is essential because Xàtiva housed the largest concentration of Mudejars in the kingdom of Valencia.

In order to recover the history of this aljama, it is necessary to consult all the documentary sources in which the voice of the Mudejars can be directly or indirectly heard. We present here documents from the Cathedral Archives of Xàtiva, recently catalogued, and from the Archivo Histórico Nacional. A total of five documents from the first half of the fourteenth century provide information about the economic status of the Mudejars of the district of Xàtiva, their financial and legal contact with Christians, bilingualism among the Mudejars, etc.

The first document studied here comes from the Archivo Histórico Nacional. It presents a dispute between the Cistercian monastery of Valldigna and the bailiate of Xàtiva regarding criminal jurisdiction over two Mudejars of Roseta, an alqueria of the district of Xàtiva, accused of committing a crime in Valldigna. What seems to be a simple dispute over criminal jurisdiction with the purpose of receiving part of the monetary penalty, becomes more complicated when a Muslim from Valldigna, who had acted as gobetween Xàtiva and Valldigna, was accused of being a renegade. The document, furthermore, suggests other important issues, such as which official decided legal cases among Mudejars; the effect that the increase of Christian presence had over Mudejars in the kingdom of Valencia, especially in rural areas, where contact with the Christian community was less frequent than at the urban aljamas, etc.

The second set of documents comes from the Cathedral Archives of Xàtiva. It presents the legal contracts between five Mudejars from Beniatjar, in the district of Xàtiva, and a Christian from the same city. The Mudejars worked the land under the direct dominium of the said Christian from Xàtiva. In addition to the conditions of labor and ownership of the land, these parchments, as in the previous case, illustrate that, at this time, Mudejars in rural areas were not able to evade Christian influence. For example, to write a deed of sell among two Mudejars concerning half of the property in question, the Mudejars went to a Christian notary. 